\title{
WHEN IS COMMUNITY-BASED MONITORING EFFECTIVE? EVIDENCE FROM A RANDOMIZED EXPERIMENT IN PRIMARY HEALTH IN UGANDA
}

\author{
Martina Björkman \\ IGIER, University of Bocconi, \\ and CEPR
}

\author{
Jakob Svensson \\ IIES, Stockholm University, \\ and CEPR
}

Evidence from recent randomized field experiments on community-based monitoring reveals substantial heterogenous treatment effects. Using data from a randomized experiment in primary health in Uganda, we test whether social heterogeneity can explain why some communities managed to push for better health service delivery while others did not. The results suggest that income inequality, and particularly ethnic fractionalization, adversely impact collective action for improved service provision. (JEL: H41, I19, O15 )

Acknowledgement: We thank Alberto Alesina and Ekaterina Zhuravskaya for sharing their data on ethnolinguistic fractionalization, Kjetil Bjorvatn, participants at the 2009 EEA conference in Barcelona, and specifically Erik $\varnothing$. Sørensen for valuable comments. Financial support from the Swedish International Development Agency, Department for Research Cooperation and Handelsbanken's Research Foundations is gratefully acknowledged.

Email: Björkman: martina.bjorkman@unibocconi.it; Svenssson: jakob.svensson@iies.su.se. 


\section{Introduction}

Access to quality services has been recognized as fundamental for wellbeing and economic development. However, in Africa and other developing countries, service delivery is often poor or nonexistent. ${ }^{1}$ Many argue that government bureaucracies may be ill equipped and lack incentives to improve the quality of public services. In response, development practitioners have started to experiment with involving beneficiaries in monitoring public service delivery and making service providers accountable to users. How best to design such interventions, and the impact of them, have been addressed in a handful of recent randomized field experiments. The results, to date, are mixed. While Banerjee et al. (2008) and Olken (2007) report minor or no effects on learning outcomes (in a project in primary education in India) and on corruption (in a road construction project in Indonesia), Björkman and Svensson (2009) and Duflo et al. (2009) report large positive improvements on average in a primary health intervention in Uganda and a primary schooling intervention in Kenya, respectively. What can explain these diverging findings? And more specifically, to what extent does the local sociopolitical environment influence users' ability and willingness to monitor public service providers?

Using data from Björkman and Svensson (2009), linked to recently assembled data on ethnic and linguistic composition at the sub-national level for Uganda (Alesina and Zhuravskaya, 2008), and income data from the Uganda National Household Survey 2005 (UNHS, 2005), we test whether social heterogeneity, in income and ethnicity, can explain why some communities managed to push for better health service delivery while others were less successful. The results suggest that income inequality and, particularly, ethnic fractionalization adversely impact collective action for improved service provision.

\section{The testing ground and the intervention}

In response to perceived weak health care delivery at the primary level, a pilot project (Citizen report cards) aimed at enhancing community involvement and monitoring in the delivery of primary health care was initiated in rural areas in Uganda in $2004 .^{2}$ The main objective of the intervention was to strengthen providers' accountability to citizen-clients by initiating a process, using trained local actors (CBOs) as facilitators, that the communities themselves could manage and sustain.

The project was implemented as a randomized field experiment in 50 public dispensaries, and corresponding catchment areas, in nine districts covering all four regions of

\footnotetext{
${ }^{1}$ Inadequate service delivery is also reflected in the poor results in terms of health and education outcomes. In Africa, many health and education indicators are dismal and of the approximately 5 million children under five that die each year, more than half will die of diseases that could easily have been prevented or treated if the children had had access to a small set of proven, inexpensive services (Black et al. 2003; Jones et al. 2003). Chaudhury et al. (2006) and Reinikka and Svensson (2004), among others, provide systematic evidence of public service delivery failures.

${ }^{2}$ See Björkman and Svensson (2009) for details.
} 
Uganda. Based on a small empirical literature on community participation and oversight, and extensive piloting in the field, Björkman and Svensson (2009) hypothesize that lack of relevant information on the status of service delivery and the community's entitlements, and failure to coordinate expectations and actions, were holding back initiatives to pressure and monitor the provider. Relaxing these two constraints was therefore the main objective of the intervention and viewed as a way to stimulate the community to more systematically use nonpecuniary mechanisms such as social rewards for well-performing health workers and sanctions against shirking ones.

The intervention contained a series of facilitated meetings: a community meeting; a staff meeting; and an interface meeting, in which baseline information on service provision (so-called report cards) were discussed and analyzed. Community members were also encouraged to develop a plan to identify key problems and steps that should be taken to improve health service provision. The final outcome of the three meetings was a shared action plan, or a contract, outlining the community's and the service provider's joint agreement on what actions needs to be taken in order to improve local health service delivery, how this was to be done, by when and by whom, and how these actions could be monitored. The three separate meetings aimed at kick-starting the process of community monitoring. After the initial meetings the communities were themselves in charge of establishing ways of monitoring the provider.

The community-based monitoring intervention resulted in large improvements in service delivery and health outcomes. One year after the intervention, treatment communities were more involved in monitoring the providers and the health workers appeared to exert higher effort to serve the community. Björkman and Svensson (2009) document large positive effects on both the quality - increased weight-for-age z-scores and markedly lower number of deaths among children under five - and in the quantity of care - large increases in utilization. However, while the average treatment effects are large and positive, Björkman and Svensson (2009) also provide indirect evidence of heterogenous treatment effects.

\section{Why would polarization matter?}

A wave of research, undertaken in both developed and developing countries, has identified ethnic diversity as an important source of variation across communities in the level of public good, but have not been able to empirically measure the channel through which this happens. ${ }^{3}$ Habyarimana et al. (2007) is an exception. They run a series of experimental games in the slum neighborhoods of Kampala, Uganda. The area is characterized by high levels of ethnic diversity and low levels of public good provision. They find that public good provision is higher in homogeneous groups, and argue that

\footnotetext{
${ }^{3}$ See for instance Alesina and La Ferrara (2000); Alesina, Baquir, and Easterly (1999); and Gugerty and Miguel (2004). Banerjee et al. (2006) discuss and review the literature.
} 
this is driven by the fact that social networks with cooperation-facilitating norms exist within, but not across, ethnically homogenous groups.

If co-ethnics expect that cooperation with co-ethnics will be reciprocated but cooperation with non-ethics will not, as Habyarimana et al. (2007) suggest, then the likelihood that the community can overcome the free-rider problems inherent in public action is higher in homogenous communities where the norm/social institution applies to everyone, than in heterogenous communities where it only applies to a smaller set of potential cooperating partners. Furthermore, communities that are more homogenous in terms of ethnicity and income should be able to more systematically incentivize the health workers through the use of nonpecuniary social rewards and sanctions.

\section{Data and specification}

We use a smaller subset of the data in Björkman and Svensson (2009). Specifically, we exploit detailed utilization data - on out-patients, delivery, antenatal care, and family planning - obtained directly from records kept by facilities for their own need (i.e. daily patient registers). ${ }^{4}$ The data set covers 50 primary health care providers in nine districts in Uganda of which half took part in the experiment (the remaining constitute the control group).

To construct a measure of ethnic heterogeneity, we exploit information on ethnic and linguistic composition at the sub-national (district) level for Uganda from Alesina and Zhuravskaya (2008). Our measure of ethnic diversity is the index of ethno-linguistic fractionalization (denoted $E L F$ ), defined as

$$
E L F_{d}=1-\sum_{n=1}^{N_{d}} p_{n}^{2}
$$

where $p_{n}$ indicates the share of group $n$ in the total population in the district, and $N_{d}$ is the number of ethnic groups in district $d .^{5}$

We construct community-specific gini coefficients by combining data from Björkman and Svensson (2009) and the Uganda National Household Survey 2005 (UNHS 2005). ${ }^{6}$ Specifically, we predict household income using information on the household's type of dwelling and construction material of the roof and the external walls as independent variables, controlling for district fixed effects. We then use the predicted coefficients and estimate income using the same wealth proxies from Björkman and Svensson (2009).

\footnotetext{
${ }^{4}$ We focus on health quantity (i.e. health utilization) primarily since this was the main outcome considered in the design of the experiment in Björkman and Svensson (2009).

${ }^{5}$ Björkman and Svensson (2009) did not collect data on ethnicity and we can therefore not estimate catchment area specific ethnic fractionalization. In this paper, we therefore use data on district-level ethnicity and assume that local heterogeneity mirrors district-level heterogeneity.

${ }^{6}$ We need to estimate income since the Björkman and Svensson (2009) data includes proxies of wealth but does not include any income measures.
} 
Finally, we use the estimated income to calculate the gini coefficient (denoted $G I N I_{j}$ ) for all 50 communities.

We focus on two sets of outcome measures: utilization and summary measures of the extent of community monitoring. Björkman and Svensson (2009) create a summary measure of community monitoring by combining six monitoring and information outcomes. We disaggregate their measure to one focusing on actions taken by the community to monitor the provider, including indicator variables for whether the health facility has put in place (i) a suggestion box for complaints and recommendations; (ii) numbered waiting cards for its patients; (iii) a poster informing about free health services; (iv) a poster on patients' rights and obligations, and one focusing on information and awareness in the community, including (i) whether households discussed the functioning of the health facility at Local council meetings during the past year; and (ii) whether households received information about the health unit's management committee ${ }^{7}$. The summary index $A C T I O N[I N F O]$ is the first component from a principal components analysis of the four monitoring [two information/awareness] variables. Table 1 reports summary statistics pre and post treatment.

To assess whether social heterogeneity can explain why some communities managed to push for better health service delivery in response to the intervention while others did not, and given the fact we have $K$ related outcome variables, we follow Kling et al. (2004) and estimate a seemingly unrelated regression system,

$$
Y=\left[I_{K} \otimes(T S H \times T S H X)\right] \theta+v,
$$

where $Y=\left(Y_{1}^{\prime}, . Y_{K}^{\prime}\right), Y_{k}$ is a vector of values for outcome $k, I_{K}$ is a $K$ by $K$ identity matrix, $T$ is an indicator variable for assignment to treatment, $S H=\{E L F G I N I\}$, and $X$ is a vector of pre-intervention facility-specific covariates. ${ }^{8}$ Standard errors are clustered at the unit of variation for ethnic heterogeneity, i.e. district level. ${ }^{9}$

We then derive average standardized interaction effects for the two social heterogeneity variables, $\hat{\gamma}^{S H}=\frac{1}{4} \sum_{k=1}^{4} \frac{\hat{\gamma}_{k}^{S H}}{\hat{\sigma}_{k}^{S H}}$, where $\hat{\gamma}_{k}^{E L F}$, for example, is the point estimate on $E L F \times T$ in the k:th outcome regression jointly as element of $\theta$ in (2), and $\hat{\sigma}_{k}^{E L F}$ is the standard deviation of the control group for outcome $k$.

\footnotetext{
${ }^{7}$ The Health Unit Management Committee (HUMC) should be the main link between the community and the facility and should monitor the day-to-day running of the facility. Each dispensary has an HUMC with members from both the health facility and non-political representatives from the community.

${ }^{8}$ We include $X$ in order to improve estimation precision and to account for stratification and chance differences between groups in the distribution of pre-random assignment (Kling, Liebman, and Katz, 2007). The results are similar, although slightly less precise, if the variables in $X$ are dropped.

${ }^{9}$ There are 9 districts. Clustered standard errors are biased in small samples, although the extent and direction of the bias is not entirely clear.
} 


\section{Results}

Table 2 reports the results for utilization. The average standardized interaction effects are large and precisely estimated, particularly for ethnic fractionalization. That is, the treatment effect is significantly larger in communities that are more homogenous in terms of ethnicity and income. For ethnic fractionalization, three of four individual effects $(E L F \times T)$ are significantly negative. The interaction term on income inequality $(G I N I \times T)$ is significantly different from zero for two of the four outcome measures. ${ }^{10}$

The interaction effects are quantitatively important. In the last four rows of table 2 we report the implied treatment effect at the $25^{\text {th }}$ and $75^{\text {th }}$ percentile of ELF and GINI. While the treatment effects are small in socially heterogeneous communities, they are large (and significantly positive) for homogenous communities.

We hypothesize that the likelihood that the community and the health clinic can come to an agreement on improving service provision and overcome the free-rider problems inherent in community-monitoring, is higher in homogenous communities where the norm/social institution applies to everyone, than in heterogenous communities where it only applies to a smaller set of potential cooperating partners. Furthermore, communities that are more homogenous in terms of ethnicity (and income) should be able to more systematically incentivize the health workers through the use of nonpecuniary social rewards and sanctions. In table 3 we try to assess this hypothesis.

The intervention aimed at relaxing two constraints; (i) lack of relevant information on the status of service delivery and the community's entitlements; and (ii) failure to coordinate expectations and actions, so as to stimulate the community to more systematically use nonpecuniary mechanisms such as social rewards for well-performing health workers and sanctions against shirking ones. The process indices $I N F O_{j d}$ and $A C T I O N_{j d}$ are measures on to what extent these constraints were in fact relaxed.

If public action (to ensure that the agreements in the community contract/action plan were implemented) is more likely to take place in more homogenous communities, we expect to find an effect on ACTION. If the degree of social heterogeneity also impacts the flow of information and the willingness to discuss issues regarding the health facility it should also impact INFO.

Table 3 reports the finding from estimating (2) with $A C T I O N_{j d}$ and $I N F O_{j d}$ as dependent variables. We start by estimating a restricted specification where we condition treatment on ethnic fractionalization only. Although both indices are proxy measures of what actions the community took (ACTION) and the community's information set $(I N F O)$, the results reveal a clear pattern: In ethnically homogeneous communities, more actions to monitor the provider have been put in place following the interven-

\footnotetext{
${ }^{10}$ Replacing the district fixed effects with ELF does not change the results. The coefficients on ELF is negative for all four utilization outcomes. The standardized effect of ELF across the for outcomes is marginally insignificant.
} 
tion, while there is no difference in the variation in knowledge or discussions about how to improve service provision between more and less homogeneous communities. Thus, while the intervention, as intended, resulted in a more engaged community that discussed health service provision (column 2), the evidence suggests that more fractionalized communities had problems of turning this activity to action (column 1). The implied treatment effect at the $25^{\text {th }}$ and $75^{\text {th }}$ percentile of ELF is 1.0 and 0.56 , respectively. The mean (standard deviation) of ACTION in the control group is -0.42 (0.66). In columns (iii) and (iv) we add GINI and GINI $\times T$. As there is less variation in the process variables $A C T I O N$ and INFO than in the utilization outcomes, by running the full specification we run into problems of multicollinearity. However, while the standard errors more than double for both the assignment to treatment indicator and the interaction term $E L F \times T$, we cannot reject the hypothesis of equal coefficients on $E L F \times T$ and $T$ in specifications (i) and (iii). There is no evidence of a relationship between income inequality and public action. While this result speaks against our main hypothesis (for income polarization), it is important to stress that both the income measure and the process variables $A C T I O N$ and INFO are measured with large errors, so the cards are stacked against finding an effect.

Figures 1 and 2, which report scatterplots of out-patients and ACTION means for the treatment and control groups in each of the nine districts, link the results in tables 2 and 3. We report scatterplots separately for the group of districts with relatively low ethnic fractionalization (i.e. those with an ELF smaller than the mean ELF in the sample) and the group of districts with relatively high ethnic fractionalization (i.e. those with an ELF higher than the mean ELF in the sample). ${ }^{11}$ Following the intervention, more homogeneous communities managed to turn the engagement into actions, here proxied by a set of accountability tools put in place at the facility. They also experience large improvements in utilization (figure 1). In less homogeneous communities, qualitatively, we observe a similar pattern but the difference between treatment and control group outcomes in both public action and utilization is much smaller (figure 2).

\section{Concluding remarks}

As policymakers in developing countries search for ways to improve health and education for the poor, it is becoming clear that more is required than just additional funds. A key obstacle to better public services looks to be the weak incentives that providers

\footnotetext{
${ }^{11}$ The values are normalized so that each district has mean 0 . We plot the average values by group (treatment and control) for each district for outpatients and ACTION expressed in standard deviation units relative to the control group overall standard deviation for each variable. Note that the implied regression line in these scatterplots is the 2SLS estimate of $\delta$ in the regression outpatient $_{j d}=\delta A C T I O N_{j d}+\eta_{d}+\varepsilon_{j d}$, where $\eta_{d}$ is district fixed effect, and using district-by-treatment interactions as instruments. A short description of the methodology is in Björkman and Svensson (2009). For further details see Kling et al. (2007).
} 
face. Schools and health clinics are not open when they should be. Teachers and health workers are frequently absent from schools and clinics, and even when there, they spend significant time not serving the intended beneficiaries. Equipment, even when working, is not used. Drugs are misused, and public funds are expropriated. In response, a growing number of experts argue that more emphasis must be placed on strengthening beneficiary control - that is, strengthening providers' accountability to citizens/clients.

While there is evidence that such an approach can have large positive effects on service provision, there is also evidence of significant variation in outcomes. Using data from a randomized experiment in Uganda, we show that social heterogeneity, and specifically ethnic fractionalization, adversely impact collective action for improved service provision. As a result, the intervention resulted in a smaller increase in the quantity of primary health care provision in heterogeneous communities.

Our results have implications for both the design and evaluation of interventions aimed at strengthening beneficiary control in public service delivery programs. On program design, interventions should be adjusted to the local sociopolitical situation. As little is known about how this is to be done, our results open up an important agenda for research: How to enhance collective action in socially heterogeneous communities. On evaluation, ideally the researchers should design the evaluation protocol so as to be able to assess the impact conditional on the sociopolitical environments. 


\section{References}

Alesina, Alberto, and Eliana La Ferrara, 2000, "Participation in Heterogeneous Communities", Quarterly Journal of Economics, Vol. 115(3), p. 847-904.

Alesina, Alberto, Reza Baqir and William Easterly (1999), "Public Goods and Ethnic Divisions," Quarterly Journal of Economics Vol 114(4), p. 1243-1284.

Banerjee, A., L. Iyer, and R. Somanathan, 2006, "Public Action for Public Goods", Working Paper, MIT.

Banerjee, Abhijit, Rukmini Banerji, Esther Duflo, Rachel Glennerster, and Stuti Khemani (2008), "Pitfalls of Participatory Programs: Evidence from a Randomized Evaluation in Education In India", NBER Working paper No. 14311.

Björkman, Martina and Jakob Svensson (2009), "Power to the People: Evidence from a Randomized Field Experiment on Community-Based Monitoring in Uganda", Quarterly Journal of Economics 124 (2): 735-769.

Black, Robert E., Saul S. Morris, and Jennifer Bryce, "Where and Why are 10 million Children Dying Every Year?," Lancet, 361 (2003), 2226-34.

Bryce, Jennifer, Shams el Arifeen, George Pariyo, Claudio F. Lanata, Davidson Gwatkin, and Jean-Pierre Habicht, the Multi-Country Evaluation of IMCI Study Group, "Reducing Child Mortality: Can Public Health Deliver?," Lancet, 362 (2003), 159-64.

Chaudhury, Nazmul, Jeffrey Hammer, Michael Kremer, Karthik Muralidharan, and F. Halsey Rogers, "Missing in Action: Teacher and Health Worker Absence in Developing Countries," Journal of Economic Perspectives, 20 (2006), 91-116.

Dulfo, E., Pascaline Dupas, and Michael Kremer, 2009, "Additional Resources versus Organizational Change in Education: Experimental Evidence from Kenya, Working Paper, MIT.

Gugerty, Mary Kay and Edward Miguel (2005), "Ethnic Diversity, Social Sanctions, and Public Goods in Kenya," Journal of Public Economics 89(11-12): 2325-2368.

Habyarimana, James, Macartan Humphreys, Dan Posner and Jeremy Weinstein (2007), "Why Does Ethnic Diversity Undermine Public Goods Provision? An Experimental Approach," American Political Science Review 101.04: 709-725.

Kling, Jeffrey R., Jeffrey B. Liebman, and Lawrence F. Katz, "Experimental Analysis of Neighborhood Effects," Econometrica, 75 (2007), 83-119.

Kling, Jeffrey R.,Jeffrey B. Liebman, Lawrence F. Katz, and Lisa Sanbonmatsu, "Moving To Opportunity and Tranquility: Neighborhood Effects on Adult Economic SelfSufficiency and Health from a Randomized Housing Voucher Experiment," Princeton University Working Paper No. 5, 2004.

Olken, Ben (2007), "Monitoring Corruption: Evidence from a Field Experiment in Indonesia", Journal of Political Economy 115 (2): 200-249.

Reinikka, Ritva, and Jakob Svensson, "Local Capture: Evidence from a Central Government Transfer Program in Uganda," Quarterly Journal of Economics, 119 (2004), 679-705. 
TABLE 1 . Summary statistics

\begin{tabular}{lccc}
\hline Variables & $\begin{array}{c}\text { Treatment } \\
\text { group }\end{array}$ & $\begin{array}{c}\text { Control } \\
\text { group }\end{array}$ & Difference \\
\hline Out-patient care (pre treatment) & 593 & 675 & -82 \\
& $(75)$ & $(57)$ & $(94)$ \\
Delivery (pre treatment) & 10.3 & 7.5 & 2.8 \\
& $(2.2)$ & $(1.4)$ & $(2.6)$ \\
ELF (pre treatment) & 0.35 & 0.36 & -0.01 \\
& $(.03)$ & $(.03)$ & $(.05)$ \\
GINI (pre treatment) & 0.096 & 0.085 & 0.01 \\
& $(.01)$ & $(.01)$ & $(.014)$ \\
Out-patient care (post treatment) & 768 & 661 & $107^{*}$ \\
& $(234)$ & $(175)$ & $(65)$ \\
Delivery (post treatment) & 15.5 & 9.2 & $6.3^{*}$ \\
& $(14.3)$ & $(8.1)$ & $(3.3)$ \\
ACTION (post treatment) & 0.42 & -0.42 & $0.84^{* * *}$ \\
& $(1.25)$ & $(.66)$ & $(.28)$ \\
INFO (post treatment) & 0.47 & -0.47 & $0.94^{* * *}$ \\
& $(1.26)$ & $(1.19)$ & $(.32)$ \\
\hline
\end{tabular}

Notes: Catchment area/health facility averages for treatment and control group and difference in averages. Robust standard errors in parentheses. Significantly different from zero at $99(* * *), 95(* *)$, and $90\left(^{*}\right)$ percent confidence level. Description of variables: Out-patient care is average number of patients visiting the facility per month for out-patient care. Delivery is average number of deliveries at the facility per month. ELF is an index of ethno-linguistic fractionalization. GINI is a community-specific Gini coefficient. ACTION in an index of monitoring tools put in place in the health clinic. INFO is an index on information and awareness in the community. See main text for details. 
TABLE 2. Impact on utilization/coverage

\begin{tabular}{lccccc}
\hline Dep. variable & $\begin{array}{c}\text { Out- } \\
\text { patients }\end{array}$ & Delivery & Antenatal & $\begin{array}{c}\text { Family } \\
\text { planning }\end{array}$ & $\begin{array}{c}\text { Average } \\
\text { std effect }\end{array}$ \\
\hline PANEL A: Björkman \& Svensson (2009) & $(\mathrm{i})$ & $(\mathrm{ii})$ & $(\mathrm{iii})$ & $(\mathrm{iv})$ & (v) \\
Program impact & $130.2^{* *}$ & $5.3^{* *}$ & 15.0 & 3.4 & $0.46^{* * *}$ \\
Observations & $(60.8)$ & $(2.1)$ & $(11.2)$ & $(3.2)$ & $(0.16)$ \\
\hline PANEL B: Panel data & 50 & 50 & 50 & 50 & \\
Program impact & $(\mathrm{vi})$ & $(\mathrm{vii})$ & $(\mathrm{viii})$ & $(\mathrm{ix})$ & $(\mathrm{x})$ \\
& 592.2 & $33.9^{* * *}$ & $118.4^{* * *}$ & $21.3^{* *}$ & $2.70^{* * *}$ \\
ELF $\times$ Program Impact & $(372.7)$ & $(11.6)$ & $(22.7)$ & $(9.79)$ & $(0.56)$ \\
& -754.9 & $-53.0^{* * *}$ & $-152.3^{* * *}$ & $-35.8^{* * *}$ & $-3.87^{* * *}$ \\
GINI $\times$ Program Impact & $(613.4)$ & $(19.5)$ & $(43.3)$ & $(10.1)$ & $(1.30)$ \\
& -2134 & $-121.8^{* * *}$ & $-596.9^{* * *}$ & -62.6 & $-10.2^{* * *}$ \\
Observations & $(1967.7)$ & $(54.9)$ & $(133.7)$ & $(52.7)$ & $(2.01)$ \\
Mean control group 2005 & 50 & 50 & 50 & 50 & \\
Treatment effect at the $25^{\text {th }}$ percentile of ELF & 188.7 & 8.1 & 22.0 & 5.64 & \\
Treatment effect at the $75^{\text {th }}$ percentile of ELF & 75.4 & 0.17 & -0.86 & 0.27 & \\
Treatment effect at the $25^{\text {th }}$ percentile of GINI & 198.7 & 8.3 & 31.3 & 5.0 & \\
Treatment effect at the $75^{\text {th }}$ percentile of GINI & 85.6 & 1.4 & -2.13 & 1.5 & \\
\hline
\end{tabular}

Notes: Panel A reports the results from Björkman and Svensson (2009), table 5, page 754. Panel B reports program impact estimates, with standard errors clustered by district in parentheses, with district fixed effects, GINI, number of villages in catchment area, distance to nearest public health provider, indicator variable for whether the facility has a separate maternity unit, and number of staff with less than advanced A-level education included. Treatment effect at the $25^{\text {th }}\left[75^{\text {th }}\right]$ percentile of ELF (GINI) is the implied treatment effect, dY/dT, at the $25^{\text {th }}\left[75^{\text {th }}\right]$ percentile of ELF (GINI) evaluated at the mean of the GINI (ELF). ${ }^{* * *}[* *](*)$ denote significance at the 1 [5] (10) percent level. Point estimates, standard errors, and average standardized effects are derived from equation (2). Program impact measures the coefficient on the assignment to treatment indicator. Specification: First column is average number of patients visiting the facility per month for out-patient care; Second column is average number of deliveries at the facility per month; Third column is average number of antenatal visits at the facility per month; Fourth column is average number of family planning visits at the facility per month; Fifth column is average standardized effect of estimates in specification (i)-(iv) and (vi)-(ix), respectively. 
TABLE 3. Impact on community action and awareness

\begin{tabular}{lcccc}
\hline Specification & (i) & (ii) & (iii) & (iv) \\
Dep. Variable & ACTION & INFO & ACTION & INFO \\
\hline Program impact & $1.86^{* * *}$ & $0.76^{*}$ & 0.80 & 0.37 \\
& $(.46)$ & $(.40)$ & $(1.21)$ & $(.83)$ \\
ELF $\times$ Program Impact & $-3.05^{* *}$ & -0.27 & -1.34 & 0.30 \\
& $(1.43)$ & $(.88)$ & $(2.34)$ & $(1.02)$ \\
GINI $\times$ Program Impact & & & 5.40 & 2.10 \\
& & & $(6.03)$ & $(5.21)$ \\
$\chi^{2}\{$ Program impact $\}$ & & & 1.19 & \\
$\chi^{2}\{$ ELF $\times$ Program impact $\}$ & & & $1.27]$ & \\
Observations & & & 1.83 & \\
Mean control group 2005 & 50 & 50 & 50 & 50 \\
\hline
\end{tabular}

Notes: Point estimates and standard errors clustered by district in parenthesis are derived from equation (2), with ELF and GINI and baseline covariates (see notes to table 2) included. Specification: ACTION in an index of monitoring tools put in place in the health clinic. INFO is an index on information and awareness in the community. See main text for details. $\chi^{2}$ \{Program impact $\}$ and $\chi^{2}\{E L F \times$ Program impact $\}$ are the test statistics, with p-values in brackets, for the null hypotheses of equal coefficients on program impact and ELF×program impact in specifications (i) and (iii). ${ }^{* *}[* *](*)$ denote statistically significant at $1[5]$ (10) percent levels, respectively. 
Figure 1. Treatment effect conditional on the degree of ethnic fractionalization - low ethnic fractionalization

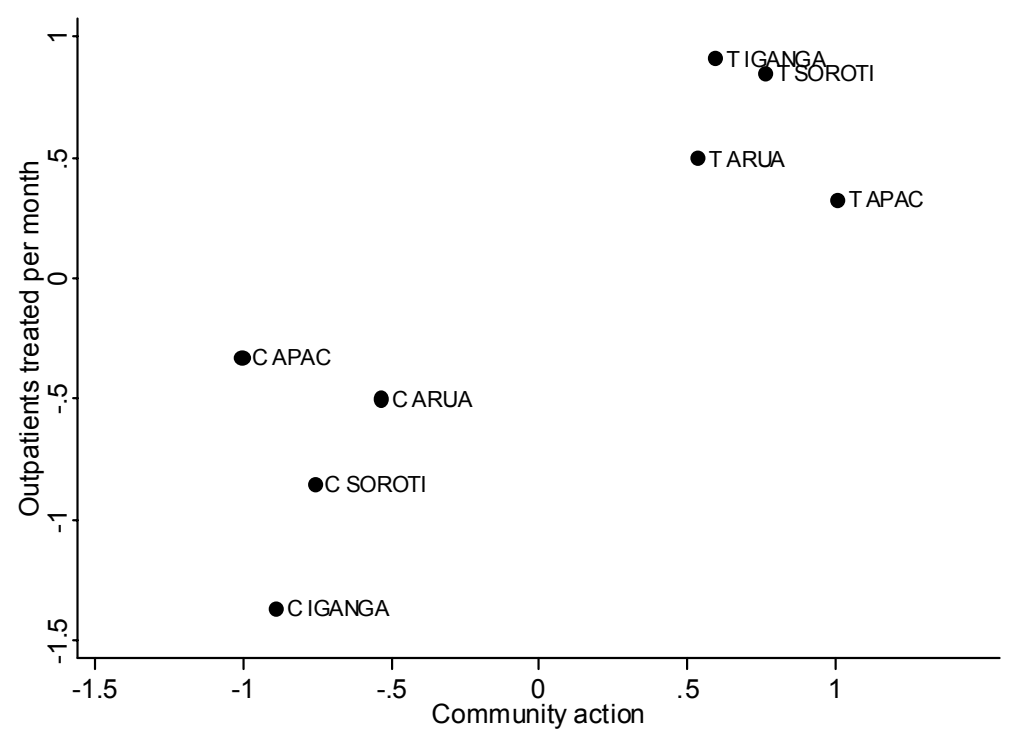

Figure 2. Treatment effect conditional on the degree of ethnic fractionalization - high ethnic fractionalization

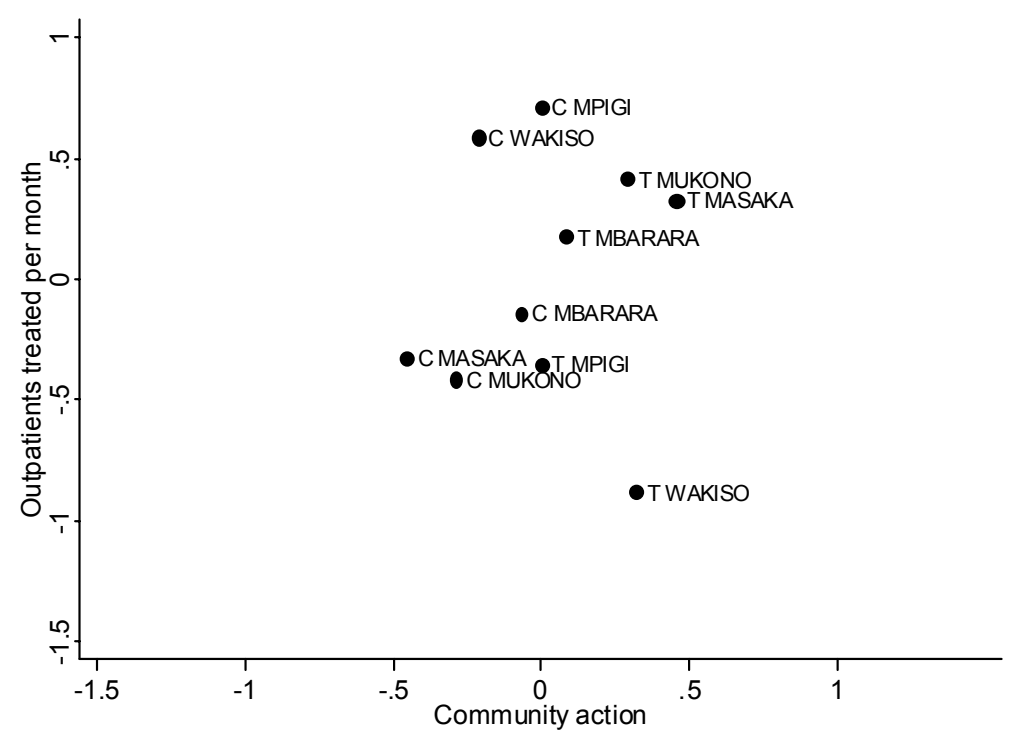

Note: Partial regression plots. The community action index and outpatients are expressed in standard deviation units relative to the control group overall standard deviation for each variable. The points are the average values by group (treatment and control) for each district, normalized so that each district has mean zero. T [C] " $\mathrm{xxx}$ " indicates treatment group average for treatment [control] clinics in district " $\mathrm{xxx}$ ". 